\title{
EVOLUCIÓN Y METABOLISMO DE UN LUGAR TRANSFORMADO POR EL TURISMO DE MASAS. UNA INTERPRETACIÓN DEL MODELO TURÍSTICO DE TORREVIEJA DESDE LA TEORÍA DE LA DEPENDENCIA DE LA TRAYECTORIA (PATH DEPENDENCE)
}

\author{
J. Fernando Vera-Rebollo, Josep A. Ivars Baidal y \\ Marco A. Celdrán Bernabeu \\ Instituto Universitario de Investigaciones Turísticas \\ Universidad de Alicante
}

En un contexto cada vez más globalizado, el futuro del turismo se juega en el reconocimiento del lugar y en la capacidad de explotar lo que le distingue.

Pié Ninot (2013, p. 35)

\section{RESUMEN}

A través de diferentes etapas y contextos, desde su configuración como lugar de veraneo a finales del siglo xIx, Torrevieja acaba consolidándose como un destino turístico de sol y playa, sobre la base de una ingente oferta construida de viviendas vacacionales y segundas residencias, que sitúa al municipio como uno de los destinos con mayor volumen total de alojamiento del arco mediterráneo español. Desde una perspectiva evolutiva y mediante el análisis de distintas fuentes de información, se identifican las etapas y el proceso de transformación de este lugar, asociado a la actividad inmobiliaria y a sus contradicciones. Con el propósito de llevar a cabo una interpretación global y ante la preocupación por sus posibles orientaciones de futuro, se aplica la teoría de la dependencia de la trayectoria, Path Dependence, que permite sistematizar las etapas clave y descifrar las principales particularidades del modelo.

Palabras clave: turismo de masas, evolución, segunda residencia, dependencia de la trayectoria. 


\begin{abstract}
Through different stages and contexts from its original establishment at the end of the nineteenth century, Torrevieja has become a sun and beach resort based on a huge range of vacation houses and second homes. By this fact it is perceived as one of the most significant resorts in the Spanish Mediterranean Coast. Implementing an evolutionary perspective and according to several information sources, stages and processes of transformation that take place are identified, closely related to real state sector. For the purpose of carrying out an overall interpretation and outline future guidelines, Path Dependence Theory is applied. This method allow us to systematize key stages and decoding the main model charasteristics.
\end{abstract}

Keywords: mass tourism, evolution, second homes, path dependence.

\title{
INTRODUCCIÓN
}

El surgimiento de Torrevieja como lugar turístico es un proceso propio de los núcleos marineros mediterráneos en los que, desde finales del siglo XIX, se generaliza la costumbre del veraneo, asociada a los baños de mar y a sus propiedades terapéuticas, favorecida en este caso por la accesibilidad que procuró un enlace ferroviario previsto inicialmente para dar salida a la producción salinera local. La atracción del mar para una clientela en un primer momento de origen comarcal y de la ciudad de Murcia, dio origen a una función económica de carácter estacional, aunque la temporada de baños de mar y el disfrute de las playas justificaron formas de ocupación y valorización de la fachada costera (establecimientos balnearios, paseos marítimos, hoteles) e incluso las primeras implantaciones de tipo residencial, con la construcción de chalés y villas, propiedad de familias acomodadas exógenas (Vera, 1984 y 1987).

El cambio de este modelo se produce esencialmente, como en tantos otros lugares, en la década de los años 60 del siglo xx, cuando el nuevo modelo de turismo que se desencadena sobre las costas cálidas de España supone la implicación urbanística del turismo, convertido en fenómeno de masas y ampliado con demanda internacional. La actividad turística, surgida en esta etapa, desde nuevos paradigmas de consumo de masas (Vera, 2001), se encuentra detrás de la transformación del sistema urbano y territorial. En este caso local, la orientación turística se decanta, desde los años del despegue, hacia la vertiente residencial, mediante la construcción de nuevos asentamientos, creados ex novo sobre la franja costera, o a base de prolongar el núcleo urbano preexistente, mediante ensanches a lo largo del eje costero. En estos nuevos espacios urbanizados se levantan edificios, con diferentes tipologías, para alojamiento estacional, como segunda residencia en propiedad o para alquileres vacacionales. De este modo, la vertiente hotelera, representativa de la época histórica del veraneo, quedaría 
postergada en el nuevo modelo y se produciría una clara preeminencia del papel de los agentes urbanizadores (promotores y constructores) en el proceso de configuración del sistema turístico local que se mantiene en la actualidad, como hecho diferencial del municipio y de la comarca en la que se localiza.

Como enmarque global del proceso, el turismo ha sido el componente principal del crecimiento de las provincias costeras españolas y es el responsable de la litoralización de ese crecimiento (Díaz, 2015). Pero el caso que justifica el presente estudio es particularmente representativo por la magnitud alcanzada en la vertiente de ocupación y transformación del territorio y por el modo en que se ha desdibujado un proceso inicial de valorización del frente de mar y se ha optado por la construcción masiva y difusa de asentamientos y la orientación casi exclusiva hacia la vertiente residencial del turismo, con numerosas contradicciones y retos.

En los primeros años ochenta del pasado siglo, cuando se diseñaba el instrumento de planeamiento municipal que posibilitó este proceso, hicimos una aproximación a las claves del surgimiento del destino turístico y a los nuevos horizontes que se perfilaban (Vera, 1984). A comienzos del presente siglo, antes del segundo gran ciclo urbanizador en el marco de la «burbuja inmobilaria», insistimos (Vera e Ivars, 2003) en la necesidad de afrontar la gestión del modelo local desde un enfoque de sostenibilidad, sobre la base de un sistema de indicadores que puso de manifiesto los contrastes que presentaba la ciudad turística, desde diferentes dimensiones: territorial-ambiental, sociocultural y económica. Ahora, con la perspectiva de tres décadas transcurridas, sobre la base de unos datos reveladores de las referidas magnitudes de cambio, retomamos el análisis y volvemos a repensar sobre el futuro del lugar turístico. Como afirman Pié y Rosa (2013), avanzando en el relato de lo próximo es como se avanza en el conocimiento de lo global.

\section{Perspectiva EVOLUTIVA DEL PROCESO DE CONFIGURACIÓN DE UNA REALIDAD TURÍSTICA-RESIDENCIAL}

La configuración como destino turístico ha pasado por distintas etapas, propias de los ciclos de vida de los lugares turísticos, desde los orígenes y formas preturísticas, para llegar al momento del despegue del proceso, en las coordenadas del turismo de masas, y alcanzar una etapa de eclosión de un modelo de crecimiento, de corte inmobiliario, que se desborda en el territorio. Finalmente, la situación actual viene marcada por las incertidumbres sobre el futuro.

\section{Los orígenes como lugar turístico}

La fundación administrativa de la actual ciudad data de 1803 y responde a la creación de un núcleo urbano de nueva planta, dedicado a la extracción y 
embarque de la sal. La actividad turística, entendida como función veraniega, se remonta al primer tercio del siglo XIX, cuando se tienen noticias referidas a la presencia estival de familias de Murcia y Orihuela, en consonancia con el auge de los baños de mar y las propiedades terapéuticas atribuidas a éstos. Una dedicación que cobra importancia con la entrada en funcionamiento del ramal ferroviario que llegaba a Torrevieja desde la línea Alicante-Murcia. Los establecimientos balnearios empezaron a formar parte del paisaje de las playas inmediatas a la localidad, además de la animación propia de un lugar de vacaciones, como prueba que ya desde los inicios del siglo xx se confeccionaran carteles anunciadores de la temporada de baños de mar (Vera, 1987), cuyo contenido refleja el esplendor alcanzado por una función que no pasaba de ser un complemento de rentas para bastantes familias, que alquilaban sus propias casas o realizaban servicios para los veraneantes. ${ }^{1}$

La villa contaba entonces, además de balnearios, con fondas e incluso un establecimiento con el nombre de Gran Hotel y Café de España y se promocionaba (1917) el Gran Balneario Vista Alegre, situado en la bahía, con cafetería y pilas de mármol. Como parte también de la nueva imagen social del lugar de veraneo, hacia 1920 se construye el Paseo de Las Rocas, trazado a lo largo del frente de mar, eje sobre el que familias acomodadas del entorno regional levantaron sus villas de recreo. Tras el paréntesis de la guerra civil, el veraneo se recupera lentamente con la construcción de nuevas villas y, sobre todo, con el alquiler de casas particulares a familias de la comarca. Pero el principal empuje a esta función se asocia con el Certamen Nacional de Habaneras (1955), por lo que supone como proyección de la imagen externa de la ciudad y de su animación en temporada estival.

Un nuevo modelo desde los años 60. Los inicios de la dimensión inmobiliaria del turismo

Desde la década de 1960, en un contexto global de cambio en el turismo, se inicia una nueva etapa en el municipio, caracterizada por la llegada de una demanda creciente procedente del ámbito internacional, además de la tradicional clientela del entorno regional. Pero la principal realidad cambiante se advierte en el modelo de implantación del turismo, que acompañará su futuro como destino y que será su rasgo diferencial, frente a otros lugares de la propia costa alicantina. Se trata de la prevalencia del modelo urbanizador, caracterizado por la construcción de viviendas y apartamentos, como modalidad de alojamiento dominante,

1. En 1912, el escritor E. Noel se refiere a la pobreza de la localidad y escribe: «Torrevieja, a merced de los caprichos del mar, de las sacudidas sísmicas, de la cosecha normal de la ciénaga, vive y no es poco. El verano la salva. En la canícula, unos miles de forasteros se pasean por aquellas calles rectas, trazadas a cordel...» (Rebollo Ortega, 2007, pp. 211-212). 
tanto en los ensanches que prolongan las alineaciones del núcleo urbano como en los numerosos asentamientos de nueva creación. Implantaciones que irán surgiendo al margen del núcleo originario de la población y que serán denominadas «urbanizaciones», como ocurre en los lugares donde el modelo turístico rápidamente se confundiría con segunda residencia y construcción. Desde ese momento, los verdaderos agentes del turismo local no serán hoteleros sino promotores y constructores, locales o foráneos, que harán del proceso de ocupación del suelo su principal objetivo, transformando de manera radical su fisonomía. Algunos son extranjeros llegados a la localidad, que levantan alojamientos para vender a sus compatriotas, entre los que destaca por su singularidad la llegada de turistas suecos, de la mano de un empresario de esa nacionalidad que promueve una colonia en lo que era entonces un paraje insólito por su valor paisajístico ${ }^{2}$. Esta etapa del despegue viene también marcada por el final de los elementos más genuinos del veraneo tradicional, como el desmantelamiento, por decisión del ayuntamiento, de los establecimientos balnearios que se mantenían en las playas y de las casetas particulares que formaban hileras sobre la arena. Mientras que al alquiler de viviendas familiares de la propia población le iba sustituyendo la adquisición de apartamentos de nueva construcción. Se sentaban las claves del «modelo Torrevieja» y aparecían así, en la segunda mitad de los años 60 , una serie de urbanizaciones particulares que valorizaban especialmente las vistas al mar. Como contrapunto a este empuje turístico, en 1970, ante su falta de rentabilidad y el creciente auge del automóvil particular y de las líneas de viajeros por carretera, se cerraba al tráfico de pasajeros la línea ferroviaria Albatera-Torrevieja, con una evidente falta de visión de futuro.

En los primeros años 70, la garantía del abastecimiento de agua potable, desde el sistema público de la Mancomunidad de los Canales del Taibilla, beneficia a este municipio como ya lo hacía con tantos otros de Alicante y Murcia (Morales y Vera, 1989). De esta forma se produce un impulso en el proceso urbanizador que está en el origen de la construcción de las primeras urbanizaciones en el perímetro de la laguna de Torrevieja, colindante con el área de explotación salinera, sobre lo que habían sido haciendas dedicadas a aprovechamiento agrario. $Y$ entra en escena un empresario de la propia comarca que crea un grupo que no tardaría en convertirse en uno de los protagonistas esenciales del modelo residencial que caracteriza al municipio, al construir miles de viviendas orientadas a un mercado masivo de propietarios de segunda residencia, tanto europeos como nacionales. La empresa, a través de una filial de su propio grupo y de una red de agentes en países europeos, se dedicaba a la comercialización

2. A este respecto, resulta particularmente interesante el relato que hace Francisco Sala Aniorte, cronista oficial de la localidad, sobre el origen de la Colonia Sueca, con el expresivo título de los turistas que vinieron del frío: http://www.cronistasoficiales.com/?p=36419 
del producto residencial, proyectando la imagen de esta población asociada a destino residencial de casas para vacaciones, o para fijar su nueva residencia, asequibles para todos los públicos. ${ }^{3}$

\section{La construcción masiva de alojamiento residencial a raiz del Plan General de} Ordenación Urbana de 1986

Los años ochenta vienen marcados por la aprobación del PGOU, que calificó suelo para dar lugar a la urbanización casi integral del término municipal, bajo la forma de planes parciales que daban pie a nuevos asentamientos. Es posible afirmar que, con la aprobación de este instrumento de planeamiento, sorprendentemente todavía en vigor, se da cauce a las enormes expectativas de inversión, ante el tirón de la demanda de propietarios para adquirir inmuebles y el papel de las empresas promotoras, verdaderos agentes del proceso, con el concurso del propio ayuntamiento que sacaba de ello enormes beneficios (licencias de obras, convenios urbanísticos, plusvalía y recaudación posterior del IBI) y la complacencia del gobierno autonómico del momento. ${ }^{4}$

La promoción de conjuntos residenciales, de bajo coste y mínima calidad constructiva fue la clave del éxito y proliferaron los nuevos asentamientos, favorecidos por los inspection tours, viajes para traer a Torrevieja y área de influencia, durante varios días, a los potenciales clientes del producto residencial, con un coste reducido, deducible del importe de la vivienda, si se acababa comprando.

Las denominadas urbanizaciones son las piezas mínimas del sistema local, en tanto los nuevos asentamientos son unidades básicas de gestión y configuración del espacio turístico-residencial. En su conjunto suman miles de hectáreas de superficie construida sobre antiguos campos de cultivo o áreas de matorral. El bajo rendimiento como áreas productivas agrícolas y el propio marco catastral (grandes o medianas propiedades como marco de las actuaciones) favoreció su transformación urbanística.

Pero no hay que olvidar en este proceso febril el papel jugado por una buena parte de la población local que, tras una larga historia de falta de expectativas en otros sectores económicos, aplaudía el ritmo vertiginoso del proceso de transformación. De un modo u otro, la promoción y construcción masiva e indiferenciada de alojamiento daba empleo directo o generaba efectos de arrastre en toda

3. La popularidad alcanzó su momento cumbre cuando el premio del más conocido concurso televisivo de aquella época, Un, dos, tres, era un apartamento en Torrevieja.

4. Prueba de ello es que Justo Quesada, el promotor más importante y principal artífice del modelo de viviendas vacacionales a precio reducido, al frente del grupo Masa, fue distinguido como «Empresario del Año de la Comunidad Valenciana», en 1987, por la Conselleria de Industria, Comercio y Turismo de la Generalitat Valenciana. Un distintivo institucional que refrendaba el modelo turístico-residencial como uno de los pilares del crecimiento económico regional. 


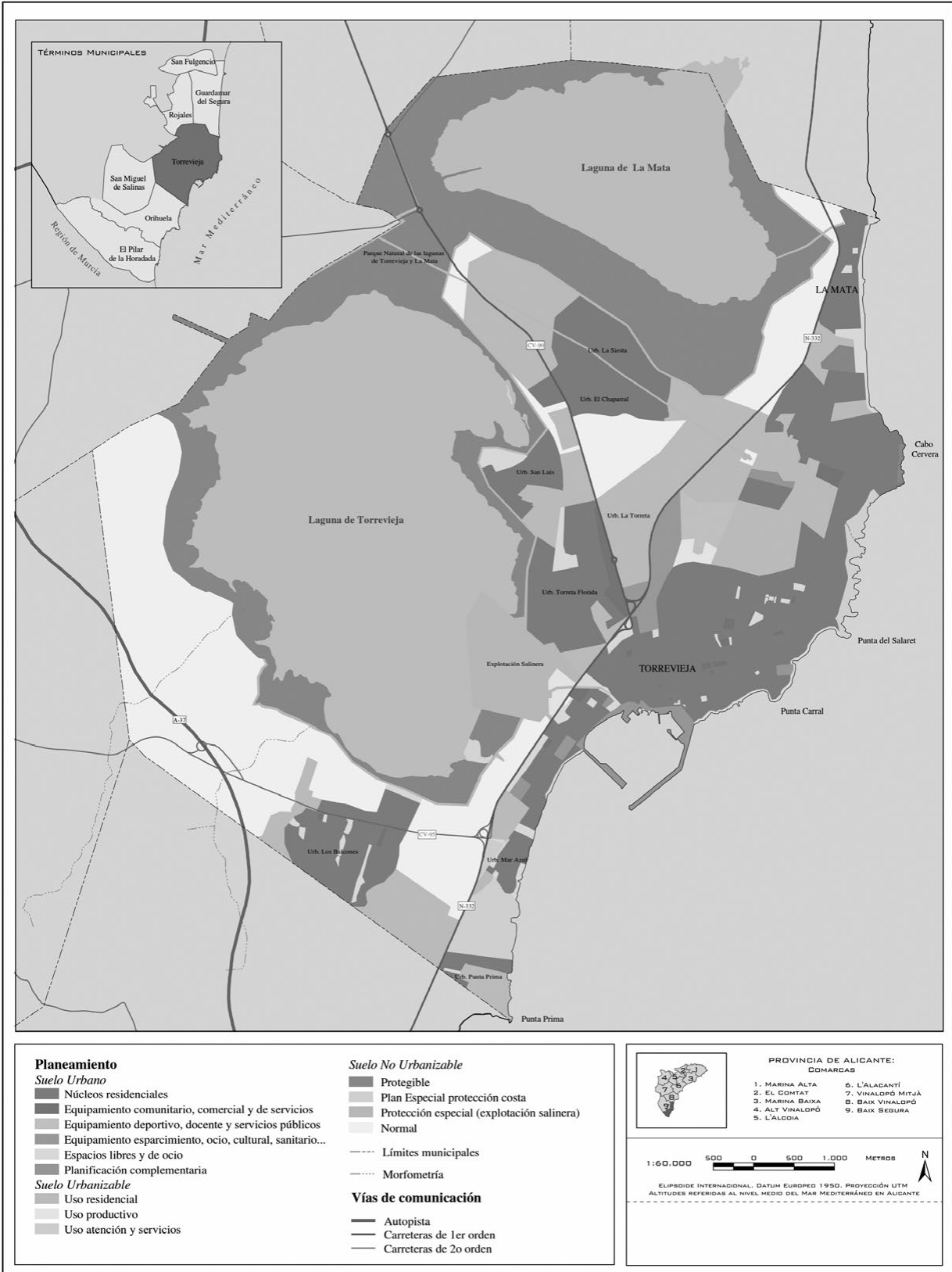

Mapa 1. Clasificación del suelo de Torrevieja. Fuente: Proyecto METASIG. 
la economía local en una dinámica que parecía no tener límites: era el mito de El Dorado aplicado a la realidad del turismo residencial.

La presión urbanizadora fue de tal magnitud que solo con la aprobación autonómica del entonces Paraje Natural (Decreto 189/1988, de 12 de diciembre, del Consell de la Generalitat Valenciana) de las lagunas de La Mata y Torrevieja se pudo frenar la expansión de los asentamientos sobre una parte sustancial del perímetro de las lagunas. De hecho, si se observa la delimitación del actual Parque Natural (3.700 ha de las que la laguna Torrevieja tiene $17 \mathrm{Km}$ de perímetro y 1400 ha; y la laguna de La Mata 700 ha) se observa la cantidad de áreas urbanizadas dentro de lo que debía ser el espacio protegido y su área de influencia inmediata.

\section{La exacerbación del modelo en las últimas décadas}

El rumbo del modelo turístico estaba ya trazado y se profundiza en él a lo largo de los años 90, con la profusión de actuaciones urbanísticas por casi toda la extensión del término municipal, en la misma línea de viviendas para el residencialismo masivo. Como balance, son escasísimos los sectores de suelo no transformado, en un paisaje compactado por la urbanización, un paisaje con burka, como le denomina Arcadi Espada (2007). El espacio protegido como parque natural es donde aún se conserva el suelo rústico, y algún tramo residual en la línea de costa (Cala Ferris, Molino del Agua). Frente al predominio de lo inmobiliario, las plazas hoteleras apenas aumentan entre 1990 y 2010 , incluso tiene lugar un hecho ilustrativo del rumbo inmobiliario del modelo de crecimiento con la adquisición del antiguo Hotel Berlín por la gran promotora Masa Internacional para servir de alojamiento circunstancial a los potenciales compradores del producto inmobiliario en los «viajes de inspección».

El indicador más claro de la voracidad del proceso inmobiliario lo establece la concesión de licencias de obras para nuevas viviendas que superaban cada año la cifra de 4.000 para alcanzar el momento culminante en el año 2000, cuando se construyen 9.030 viviendas. Como balance del periodo 1991-2003, se construyeron 54.525 nuevas viviendas en el municipio, una cifra récord que en algún año solo fue superada en España por el municipio de Madrid.

Cuando en 2003 se celebraron los fastos conmemorativos del bicentenario de su fundación administrativa, Torrevieja alcanzaba ya la cifra de 77.943 habitantes y era el quinto municipio de la Comunidad Valenciana, en cuanto a número de habitantes, por encima del rango de ciudades como Orihuela, la antigua capital comarcal del Bajo Segura, a la que desplazó durante los años 90 como centro de servicios del sur de la provincia.

Pero un crecimiento tan fulgurante no se realiza sin contradicciones y con incertidumbres sobre su futuro, sobre todo cuando el modelo económico 


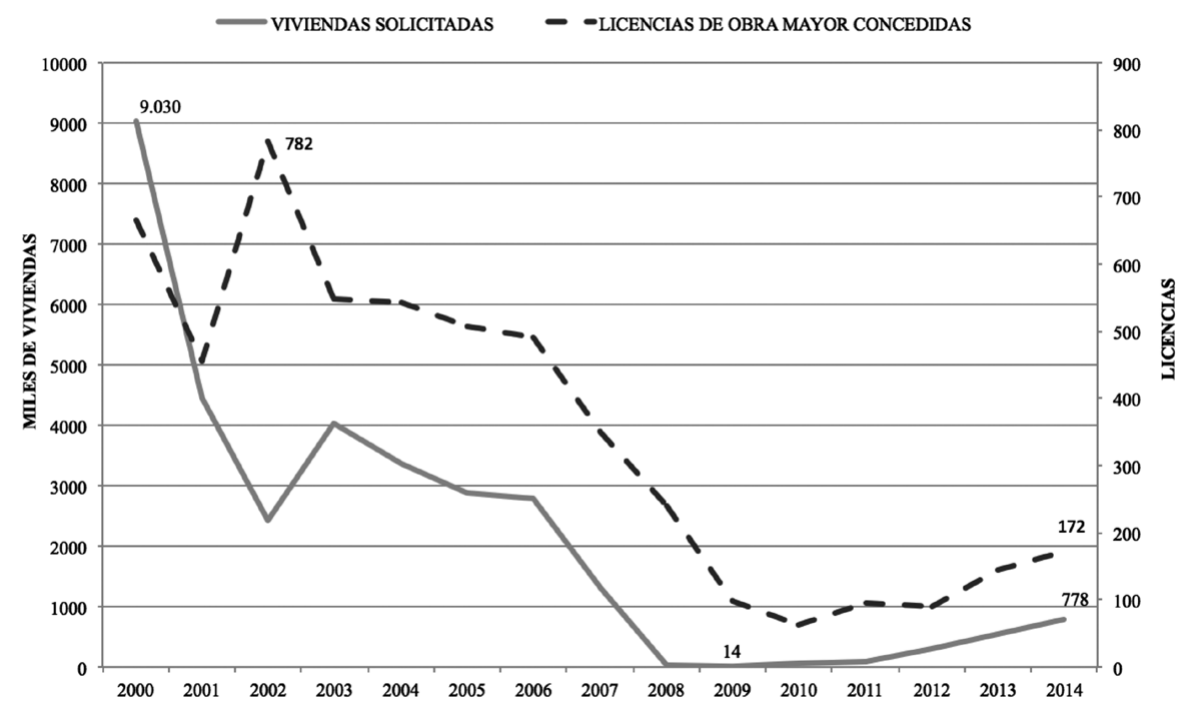

Figura 1. Viviendas solicitadas y licencias de obra mayor concedidas en Torrevieja (2000-2014).

Fuente: Área de Urbanismo del Excmo. Ayuntamiento de Torrevieja. Elaboración propia.

que la sustenta se apoya exclusivamente en el crecimiento de la función residencial-turística.

\section{El fin del ciclo de crecimiento y las incertidumbres}

La fase expansiva del ciclo inmobiliario perdura hasta la crisis severa de 2008, construyéndose desde 2003 otras 11.000 nuevas viviendas (en 2008 no se alcanzan las 1.000). Pero ha persistido el empeño por seguir creciendo en número de viviendas y transformando los escasos sectores que, calificados por el planeamiento vigente o recalificados mediante modificaciones del PGOU, aún quedaban sin urbanizar. Una parte de ese crecimiento responde a la demanda de viviendas por el asentamiento de residentes de origen extranjero. Gentes llegadas para vivir una nueva etapa de su vida en un lugar que ofrece casas baratas bajo el sol y no siempre con vistas al mar. A este respecto, entre el año 2000 y 2008 la población extranjera mantiene un crecimiento exponencial, paralizado en el período 2008-2013. Pero lo más llamativo es que a partir del año 2006 la población extranjera supera a la nacional hasta el 2013. En este último año la población extranjera alcanza su pico máximo, con un 53,21\%. La revisión del padrón municipal en 2014 merma la población extranjera empadronada, reduciéndola hasta el 45,32\%. 


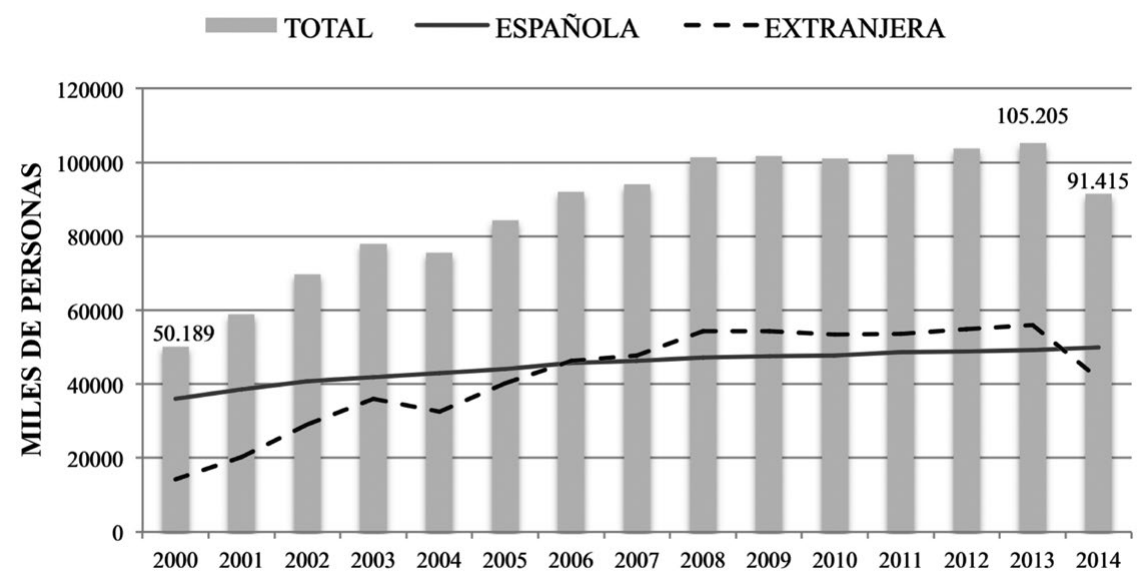

Figura 2. Evolución de la población española y extranjera (2000-2014). Fuente: Instituto Valenciano de Estadística (IVE). Elaboración propia.

El análisis de la actividad económica de la ciudad sigue revelando una marcada dependencia del sector inmobiliario que, por otra parte, ha promovido un sector servicios muy significativo. Si tomamos como referencia el número de empresas registradas según su actividad principal, obtenemos que en el año 2014 aparecen registradas un total de 5.167 empresas, cuya actividad principal es la industria $(1,97 \%)^{5}$, la construcción $(16,77 \%)$, el comercio, transporte y hostelería $(41,91 \%)$ y otros servicios $(39,32 \%)$. Las actividades inmobiliarias suponen el $11,6 \%$ de las empresas del sector servicios, mientras que el comercio, transporte y hostelería representan el 51,7\%.

Cuadro 1. Empresas según actividad principal

\begin{tabular}{|l|c|c|}
\hline \multicolumn{1}{|c|}{ ACTIVIDAD } & NÚMERO DE EMPRESAS & \% DE EMPRESAS \\
\hline Industria & 102 & 1,97 \\
\hline Construcción & 867 & 16,77 \\
\hline Comercio, transporte y hostelería & 2.166 & 41,91 \\
\hline Otros servicios & 2.032 & 39,32 \\
\hline TOTAL & $\mathbf{5 . 1 6 7}$ & $\mathbf{1 0 0}$ \\
\hline
\end{tabular}

Fuente: Instituto Nacional de Estadística (INE). Datos relativos al año 2014. Elaboración propia.

5. La explotación salinera ha sido la principal industria de la ciudad hasta la irrupción del turismo de masas (Celdrán y Azorín, 2004). En la actualidad cuenta con una plantilla de unos 80 trabajadores. 


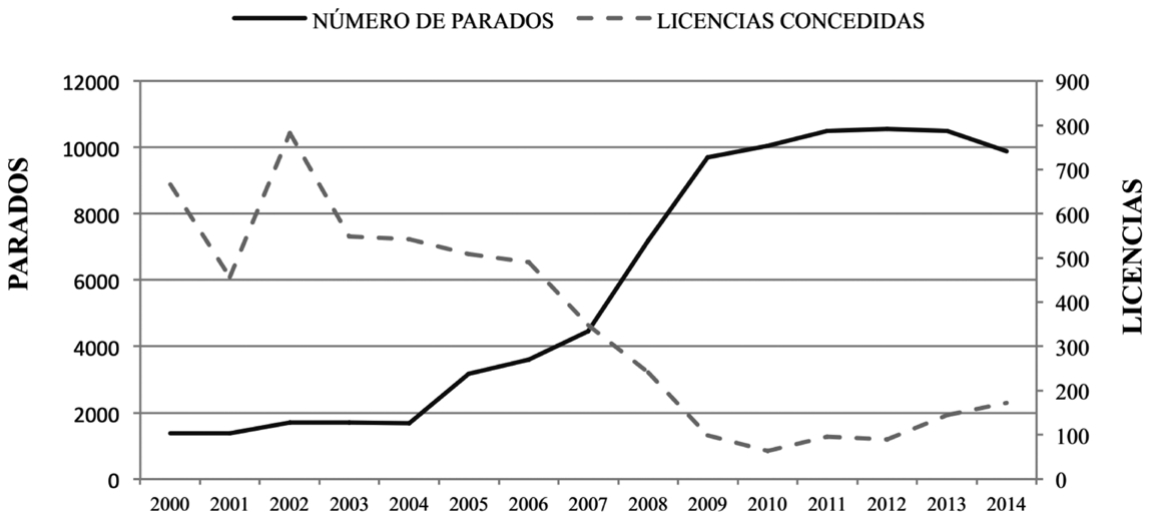

Figura 3. Relación entre el número de parados y las licencias concedidas en Torrevieja (2000-2004)

Fuente: Área de Urbanismo del Excmo. Ayuntamiento de Torrevieja. Elaboración propia.

El modelo económico-empresarial muestra de esta manera una clara subordinación al sector inmobiliario, hecho que vuelve a ponerse de relieve si estudiamos la tendencia de las licencias de obra y el paro registrado para la serie 2000-2014. En el año 2007 se inicia un caída en el número de licencias concedidas que alcanza su mínimo en el 2010 (63). En ese mismo año el número de parados se dispara para alcanzar su pico máximo en 2012 (10.557). A partir de este mismo año se vislumbra una recuperación del número de licencias que, de nuevo, guarda una estrecha relación con el número de parados, que disminuyen.

Desde el punto de vista de la rentabilidad social, el modelo de desarrollo de base inmobiliaria ha generado desequilibrios, verdaderas debilidades estructurales que pueden pasar desapercibidas en ciclos económicos expansivos y agravarse en momentos de recesión económica. Mazón y Aledo (2004) han constatado déficit en cuanto a equipamientos sanitarios (camas por habitante) o ratio de alumnos en formación por aula con respecto al promedio nacional, así como un mayor número de infracciones y delitos relacionados con la seguridad ciudadana. Recientemente, la estadística de Indicadores Urbanos del INE (2015) sitúa a Torrevieja como la ciudad con menor renta media por hogar en España: 7.987,67 euros. Esta cifra corresponde a datos de 2012 y es el resultado de dividir los ingresos que constan en la Agencia Tributaria por una estimación del número de hogares residentes en el municipio (43.649), no por el total de hogares (118.427). Aunque la singularidad de Torrevieja (volumen considerable de economía sumergida y residentes extranjeros que tributan en sus países de origen) introduce un sesgo en la estadística, el valor obtenido es sintomático de la debilidad del modelo de desarrollo. 
Paradójicamente, el contrapunto a un urbanismo indiferenciado y consumidor de territorio se ha pretendido realizar mediante grandes proyectos urbanos que tratan de ser el escaparate de una nueva ciudad. Acciones que podrían considerarse como ejercicios de marketing urbano, pero en este caso disociadas de una visión integradora, lo que parece acreditar un objetivo cosmético-político alejado de fines generalistas y racionales basados en estrategias consensuadas.

Fruto de estas iniciativas nacen actuaciones emblemáticas, como la remodelación del paseo marítimo de Juan Aparicio; el Palacio de los Deportes; el Teatro Municipal; e incluso un proyecto de Calatrava para la reordenación del puerto. Entre los más sonados y polémicos, el proyecto de balneario de lodos, encargado al arquitecto japonés Toyo Ito, ocupando el dominio público marítimoterrestre de la laguna de Torrevieja, proyecto que ahora se encuentra estado de abandono, a pesar de su elevado presupuesto. El proyecto estrella más reciente es el Auditorio Internacional de Torrevieja, inaugurado en 2011, con un coste de 53 millones de euros, que pretendía convertirse en el acicate del segmento MICE (Meetings, Incentives, Conferencing and Exhibitions) en la ciudad. Desde su inauguración permanece cerrado y con unos costes de mantenimiento de 360.000 euros anuales ${ }^{6}$. Proyectos todos con un coste nada asequible, si se atiende al nivel de endeudamiento de las arcas municipales y la merma de ingresos tras el parón de la actividad constructora.

No obstante, también en las últimas décadas se han llevado a cabo nuevas infraestructuras y equipamientos urbanos que testimonian una orientación hacia parámetros propios de una ciudad que debe afrontar el futuro de un modo diferente. Destaca en este sentido la oferta sanitaria de la ciudad, que gira en torno al Hospital Universitario de Torrevieja, el Hospital Quirón y otros centros privados.

En materia medioambiental, el municipio es otro ejemplo de las contradicciones indicadas. Por una parte, se ha conseguido eficiencia en aspectos como la gestión del ciclo integral del agua y en la recogida y tratamiento de residuos sólidos urbanos. Pero, por otra, el futuro para muchos agentes locales no se entiende sin recurrir al crecimiento urbanístico y venta de viviendas, aún a costa de perpetuar un modelo que ya ha manifestado sus consecuencias. Además, no se evidencian estrategias públicas rigurosas que lideren dinámicas económicas alternativas.

Otro de los aspectos de su nueva configuración urbano-turística es la forma en que la concentración de población ha generado crecimientos en el aparato de servicios comerciales y de ocio. Es relevante, a este respecto tener, que el

6. El Auditorio Internacional costó 53 millones de euros, diez más de lo anunciado. Diario Información de Alicante. Septiembre 2015. Disponible en: http://www.diarioinformacion.com/ vega-baja/2015/09/24/auditorio-internacional-costo-53-millones/1678106.html. 
número de habitantes empadronados se haya duplicado entre 2001 y 2011, pasando de 50.000 a casi 100.000 habitantes. La potenciación de la función ha impulsado la creación de nuevas áreas comerciales fuera del área central de la ciudad y, como contrapunto, la renovación de las calles del centro tradicional de la villa para tratar de dinamizar el comercio local, generador de numerosos puestos de trabajo, pero que está atravesando una crisis notoria. No hay que olvidar, en este sentido, que el sistema de asentamientos realizados al margen del núcleo principal de población ha contribuido a la creación de áreas comerciales en las propias urbanizaciones, en detrimento del papel del comercio en el centro de la urbe. En este momento, se localizan 16 áreas comerciales fuera de él, además de innumerables comercios individuales, consecuencia del modelo de urbanismo difuso.

Este mismo sistema de asentamientos en formas de células más o menos cerradas es la razón de que el municipio no haya logrado la suficiente cohesión social y de que se detecten problemas de degradación de ambientes urbanos, fruto del crecimiento rápido y mal planificado.

Por lo que atañe al modelo turístico, como ya hemos indicado, se ha consolidado su orientación residencial y el mejor indicador de esta especialización es que, contando con más de 275.000 plazas estimadas en viviendas vacacionales y segundas residencias, apenas hay 1.601 plazas hoteleras regladas y solo un hotel de cuatro estrellas, inaugurado en 2012. De este modo, la oferta turística municipal se caracteriza por una planta hotelera reducida. De las 1.601 plazas (786 habitaciones) dominan aquellas relacionadas con hoteles de tres estrellas $(77,6 \%)$. La plazas de una estrella representan el 14\%, mientras que las de cuatro estrellas constituyen el 8,4\%, no existiendo ningún hotel de cinco estrellas. Otra dato llamativo es el bajo número de empresas de turismo activo, solo 6. Esta cifra apoya la idea de la hiperespecialización del destino en el turismo residencial, pero del mismo modo deja ver el inicio de nuevas dinámicas relacionadas estrictamente con el turismo, ya que en el año 2013 no existía ninguna (Agència Valenciana del Turisme, 2014).

En Torrevieja no se realizan procesos de encuestación a la demanda turística, por lo que para profundizar en algunas de sus particularidades debemos analizar fuentes alternativas, como el registro de las consultas realizadas ${ }^{7}$ en las oficinas de turismo locales durante el verano de 2014 (Concejalía de Turismo del Ayuntamiento de Torrevieja). Durante este período las oficinas de turismo de Torrevieja atienden a un total de 16.856 visitantes que realizan un total de

7. Los visitantes de las oficinas de turismo no pueden calificarse como turistas sensu stricto, dado que no se realiza el preceptivo filtrado. En este registro local únicamente se anota la procedencia y el tipo de consulta, no el tiempo de estancia, tipo de alojamiento, si es turista, etc. Por tanto, son visitantes de la oficina de información, no por ello turistas. 
Cuadro 2. Oferta turística municipal

\begin{tabular}{|l|c|c|c|}
\hline \multicolumn{1}{|c|}{ Tipo } & Número & Plazas & Habitaciones \\
\hline Hotel & 12 & 1.601 & 786 \\
\hline Hostales & 2 & 59 & 28 \\
\hline Pensiones & 1 & 38 & 24 \\
\hline Apartamentos & 753 & 4.707 & - \\
\hline Campings & 1 & 761 & $227^{*}$ \\
\hline Restaurantes & 553 & 27020 & - \\
\hline Agencias de viaje & 24 & - & - \\
\hline Empresas de turismo activo & 6 & - & - \\
\hline
\end{tabular}

* Este dato representa el número de parcelas.

Fuente: Agència Valenciana del Turisme, 2014. Elaboración propia.

44.604 consultas, el 56\% realizadas por visitantes internacionales. La mayoría de estas consultas se relacionan con información local, actividades culturales o transporte, no existiendo diferencias apreciables en el tipo de consultas realizadas por visitantes nacionales e internacionales. Tampoco se aprecian diferencias entre el tipo de consultas realizadas y la época del año. No obstante, sí se aprecia que en invierno la proporción de procedencia nacional-internacional recae a favor de los visitantes internacionales. De estos visitantes internacionales, los que más visitan las oficinas municipales son ingleses $(15,62 \%)$, escandinavos $(12,8 \%)$, franceses $(10,55 \%)$ y belgas $(3,57 \%)$. Por otra parte, dentro de los visitantes nacionales, destacan los procedentes de la Comunidad de Madrid $(18,1 \%)$, País Vasco $(5,87 \%)$, Castilla y León $(4,43 \%)$ y Comunidad Valenciana $(3,26 \%)$.

El registro de consultas de las oficinas de información turística únicamente nos aproxima a una somera caracterización de sus usuarios, en cuanto a procedencias y tipo de consultas. No obstante, la Red Tourist Info Comunitat Valenciana realiza durante los meses de julio, agosto y primera quincena de septiembre una encuesta dirigida a los visitantes de estas oficinas, con el objeto de conocer el perfil del usuario, averiguar su grado de satisfacción y evaluar el nivel de calidad de las oficinas de la red. En este cuestionario sí se perfila al usuario, identificando si visita la ciudad por motivos de ocio/vacaciones, el alojamiento utilizado, medio de transporte, principales motivos de visita a la ciudad, actividades a realizar, etc. El análisis de esta encuesta nos permite alumbrar información turística de interés. En el verano de 2015 el 80,3\% de los encuestados se encontraba en Torrevieja disfrutando de una estancia de vacaciones, pernoctando en ella además. El alojamiento utilizado predominante, como 
era de esperar, es la vivienda (86,36\%), donde sobresale la vivienda alquilada y la de familiares o amigos. Tan solo un 7,57\% de los encuestados se alojaba en hotel. El principal motivo de visita a la ciudad es la playa $(78,78 \%)$, el descanso $(75,75 \%)$ y el clima $(43,93 \%)$. La principal actividad del turista es ir a la playa $(87,87 \%)$, lo que también justifica que el $77,27 \%$ de los encuestados no conozca la programación de actividades festivas y culturales.

Sin duda, el principal escollo para el futuro viene dado por el desgaste que padece su imagen como destino turístico y su percepción asociada a masificación, urbanismo de baja calidad, saturación y conflictividad, lo que le resta credibilidad para ciertos proyectos venideros. Prueba de ello son las distintas iniciativas promovidas por la corporación local con el objeto de atraer la inversión de cadenas hoteleras. Ninguna ha fructificado y dejan entrever la imposibilidad de reconducir un modelo absolutamente especializado en el residencialismo.

\section{ClaveS DE INTERPRETACIÓN DEL MODELO TORREVIEJA}

El proceso analizado permite identificar los términos para una interpretación del modelo de crecimiento inmobiliario-turístico, desde su contexto territorial de referencia y ante la necesidad de renovación y reorientación del sistema turístico local.

\section{El contexto territorial de referencia: un territorio con vocación casi metropolitana}

Torrevieja forma parte de un gran espacio turístico residencial localizado al sur de la Comunidad Valenciana, una aglomeración con morfología de corredor urbano litoral y prelitoral, que se extiende desde Guardamar del Segura hasta El Pilar de la Horadada, límite administrativo con la Región de Murcia. Un conglomerado formado por los núcleos preexistentes al turismo, transformados y ensanchados en las últimas décadas, junto con centenares de nuevos asentamientos que jalonan el eje costero y que se expanden hacia el interior, abarcando una franja con una profundidad de entre 5 y $10 \mathrm{Kms}$, delimitada por una topografía conformada por colinas y lomas, con perspectivas sobre el mar, que actúa como divisoria natural de la franja litoral, entendida como área de influencia y de desbordamiento de las dinámicas generadas por el turismo en su faceta residencial.

Si se toma como referencia estadística el número de habitantes de los municipios ribereños de este espacio (Guardamar del Segura, Torrevieja, Orihuela costa y El Pilar de la Horadada) la conurbación costera sumaría más de 150.000 habitantes permanentes (datos del Padrón Municipal de fecha 1/01/2014). Pero la cifra se incrementaría en otros 40.000 aproximadamente al incluir algunos 
municipios de segunda línea, es decir no colindantes con la costa pero en el área de influencia inmediata. En cuanto al dato de población estacional estimada, multiplicaría por 4 ese volumen de población, rondando los 800.000 habitantes en época punta de ocupación estival.

En su conjunto, se trata de un territorio polinuclear y fragmentado en numerosas unidades o piezas mínimas (urbanizaciones) bajo el común denominador de una producción masiva de alojamiento residencial y en el que, de manera planificada o por generación espontánea, han ido apareciendo nuevas centralidades (caso de la costa de Orihuela). Como «metápolis turística», este conglomerado se apoya en el eje costero de comunicación que configura la CN-332, convertida en catalizador de los procesos de urbanización desde los años 60 del pasado siglo. Mientras que la difusión de los asentamientos hacia el interior apenas cuenta con corredores transversales costa-interior, salvo la red de carreteras locales y comarcales transformada por la dinámica turística. Las intensas relaciones funcionales que se producen entre municipios vecinos no se sustentan en criterios de complementariedad ni en procesos de cooperación y colaboración necesarios, a pesar de ser un territorio fisiográficamente homogéneo y con problemas compartidos.

En Torrevieja, el PGOU ha sido, desde mediados de los años 80, el único instrumento de ordenación y gestión para dar cauce a la vorágine urbanizadora. Una ciudad construida sobre la base de consumir territorio, donde no ha habido ningún instrumento de ordenación con rango jerárquico superior al del plan municipal y toda la competencia en ordenación del suelo ha recaído en el ayuntamiento, sin que se hayan existido directrices o recomendaciones más generales respecto a distintos aspectos clave, como la ordenación del suelo urbano y urbanizable y las tipologías edificatorias, el tratamiento del suelo no urbanizable, o las grandes infraestructuras y equipamientos.

Esta ausencia de instrumentos de rango superior también justifica que no se haya puesto en marcha una estrategia conjunta de ordenación para un territorio más amplio, a pesar de las características y factores físicos y humanos que justifican claramente la consideración de una ordenación territorial de escala intermedia, abarcando una extensión mayor que los estrictos límites municipales de Torrevieja. De hecho, es evidente el desbordamiento de los procesos urbanizadores hacia municipios vecinos (San Miguel de Salinas, Orihuela, Guardamar del Segura, entre otros), con la especialización residencial como argumento, y el modo en que la actividad turística generada en el litoral impregna, de modo directo e indirecto, a la práctica totalidad de la comarca, sobre la base del modelo de accesibilidad en un territorio donde la difusión de los asentamientos hacia el interior se basa en la competencia municipal por captar inversiones inmobiliarias. 


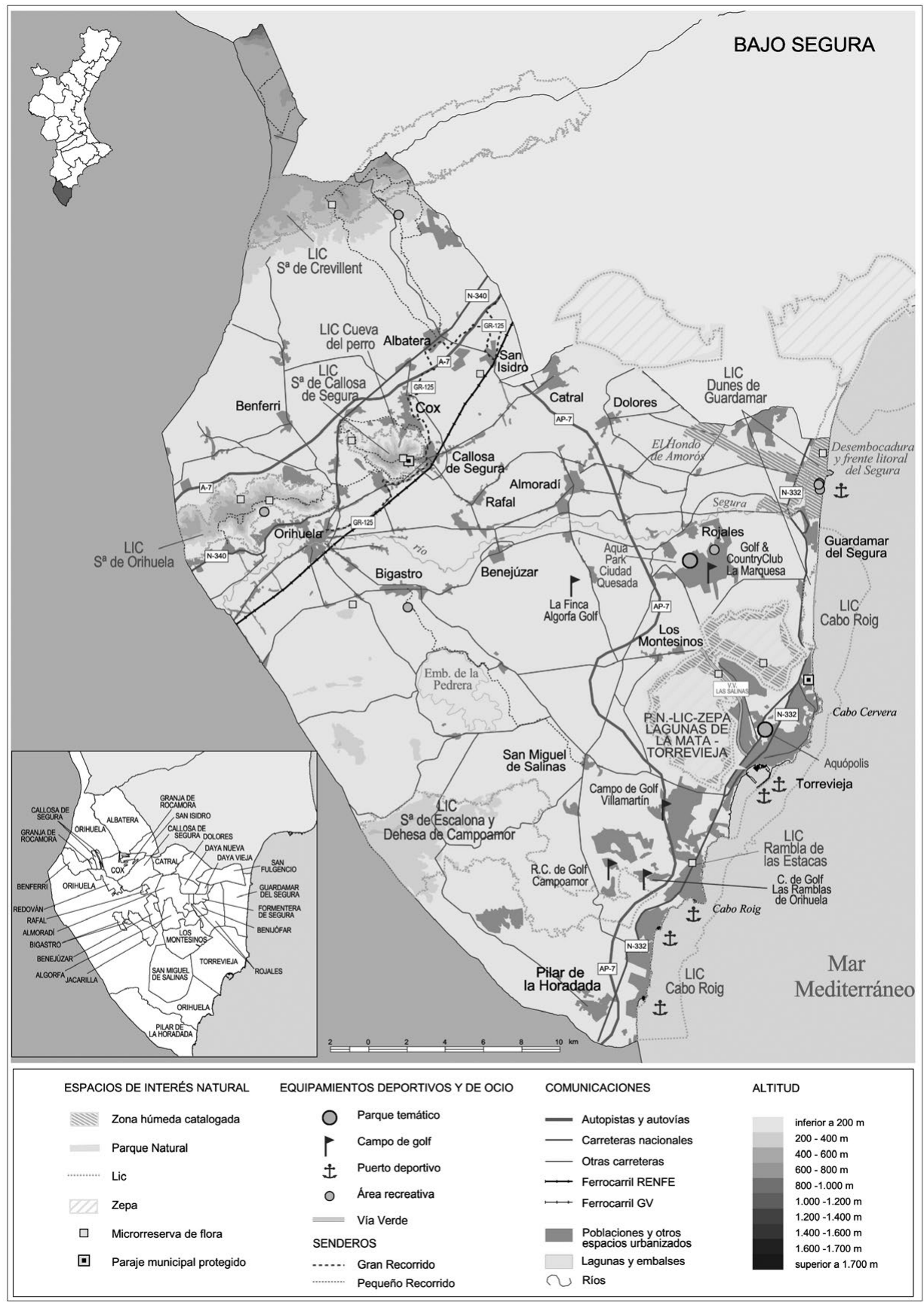

Mapa 2. Contexto territorial y turístico de Torrevieja.

Fuente: Plan de Espacios Turísticos de la Comunidad Valenciana. 
Excepción en cuanto a este esquema de prevalencia del planeamiento de base municipal es la planificación ambiental que, desde su declaración, afecta al parque natural de las Lagunas de la Mata y Torrevieja, si bien la inusual declaración y delimitación del área protegida sin tener como argumento inicial un PORN junto con el posterior retraso en contar con un PRUG son aspectos críticos que han influido en las imprecisiones de límites y, sobre todo, del área de influencia del parque, acechada por actuaciones urbanísticas, tanto en este municipio como en el vecino Guardamar del Segura, con la urbanización de la finca El Raso, ocupando parte del perímetro de protección del parque natural.

En el momento actual, es evidente la conveniencia de establecer bases de relación formal y funcional de este territorio, a partir de un instrumento normativo que oriente las relaciones de complementariedad. Esta es una de las claves de futuro en aspectos esenciales como la accesibilidad y movilidad; el tratamiento de las áreas naturales y corredores verdes de rango supramunicipal; los espacios de urbanización densa; las áreas comerciales; la gestión de los equipamientos sanitarios, culturales y deportivos; el tratamiento del frente costero, entre otros aspectos.

La realidad actual de un territorio construido. La necesaria renovación de un destino masivo

Tipologías edificatorias entremezcladas y yuxtaposición de piezas definen en la actualidad el conglomerado urbano-turístico de este municipio. La morfología dominante, además de la polarización que desempeña el núcleo urbano, es la de asentamientos autónomos, a veces segregados, conformados mediante viviendas aisladas o adosadas, en consonancia con diferentes ciclos y contextos económicos desde el lado de la demanda que adquiere las unidades residenciales. Entre 1960 y 2011 el parque de viviendas de este municipio se multiplica por 37: según el Censo de 1960, el número de viviendas familiares era de 3.345 de las que el $28^{\prime} 5 \%$ eran de uso secundario. Con los resultados del último Censo (INE, Censos de Población y Viviendas de 2011) las viviendas familiares suman 122.327, de las que el 67'4\% son de uso no principal (secundarias o vacías), lo que significa que es el segundo municipio de la provincia en número total de viviendas (más incluso que Elche, que cuenta con 227 mil habitantes en este Censo, y el primero de la provincia en número de viviendas no principales) y atestigua de manera fehaciente el grado de especialización residencial del municipio. Es significativo y testimonia el auge de la función residencial el hecho de que el incremento de 20.000 viviendas entre 2001 y 2011 responda sobre todo al mayor aumento de viviendas de uso principal y no de las de uso secundario, como venía ocurriendo anteriormente. De hecho, las de uso no principal sumaban en 2001 el $78^{\prime} 9 \%$ del total, mientras que en 2011 representan ese $67^{\prime} 4 \%$, 


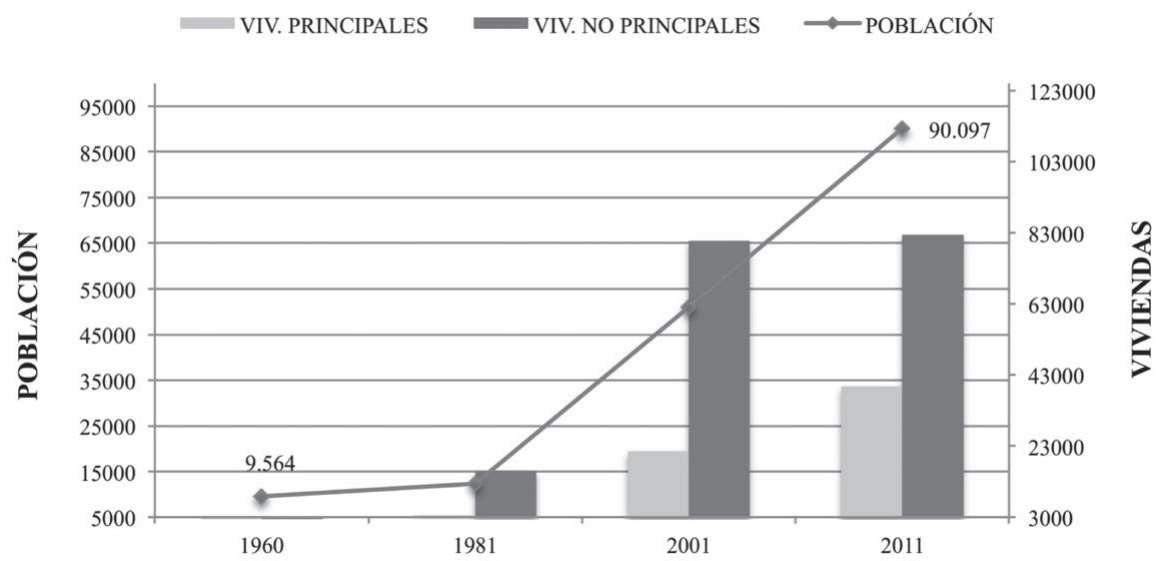

Figura 4. Torrevieja: evolución de la población de derecho y viviendas (1960-2011) Fuente: Instituto Nacional de Estadística (INE) y Vera (1984). Elaboración propia.

lo cual denota la importancia de la fijación permanente de población, en buena medida residentes de origen extranjero. ${ }^{8}$

La llegada de residentes, nacionales o de otros países, por motivos de ocio o en busca de oportunidades laborales, justifica que la población empadronada haya pasado de 9.564 habitantes de derecho en 1960 (INE, Censo de Población de 1960) a 91.415 en 2014 (Padrón Municipal). Es decir, la población se multiplica por 10 en medio siglo de transformaciones asociadas al turismo.

Suburbanización y modelo extensivo de ocupación del territorio son notas dominantes ya que el modelo turístico tiene como referencia y fundamento la componente residencial, como en tantos otros lugares del litoral mediterráneo (Fernández y Barrado, 2001; Vera, 2005), resultado tanto de las segundas residencias en propiedad, de las viviendas ocupadas por residentes casi permanentes de origen extranjero $y$, sobre todo, de la oferta de alojamiento de alquiler vacacional, no declarado como alojamiento turístico en su parte más sustancial.

8. Si se toma como referencia lo que acontece en otros municipios del litoral mediterráneo español, la mayor proporción de viviendas de uso no principal respecto al total de viviendas familiares aparece en el municipio de Oropesa (Castellón), donde las viviendas de uso no principal representan el $78^{\prime} 9 \%$ del total de viviendas del municipio. Porcentajes muy elevados, en torno al $72 \%$, se encuentran en localidades costeras de la Región de Murcia, caracterizadas por el elevado peso de la segunda residencia y apartamentos de uso estacional. Es el caso de Los Alcázares (72\% de viviendas no principales) y de San Javier (71'9\%), al incluir éste parte de La Manga del Mar Menor. Muy diferentes son las cifras cuando se trata de municipios donde se asienta un importante contingente de residentes extranjeros, empadronados en la localidad. Este sería el caso de Marbella (43'7\% de viviendas de uso no principal) y de Mijas (41' $8 \%$ ), o de San Fulgencio (Alicante), con una población extranjera residente que supera el $76 \%$ del total del municipio, mientras que las viviendas de uso no principal suman el $48 \%$ del total. 
La situación actual es paradigmática de los destinos masivos de sol y playa, en áreas consolidadas, cuyo futuro como destino turístico y residencial requiere acometer procesos de renovación urbana y cualificación en materia de paisaje y medio ambiente, además de acciones relativas a la movilidad, contención de nuevos crecimientos urbanos y una revisión de los criterios para los nuevos proyectos de oferta de alojamiento. Desde el ángulo de la reestructuración y reurbanización de los espacios turísticos maduros, se ha señalado (Rovira, 2008) que hay básicamente tres alternativas o vías de trabajo. Una alternativa de futuro pasaría por la reconversión del espacio turístico en ciudad permanente, lo cual en este caso choca con la realidad de un destino cuya ocupación sigue siendo primordialmente vacacional y estacional. Una segunda vía es la de orientar el modelo hacia la hiperespecialización turística, sobre la base de nuevos productos muy diferenciados y singularizados, para lo que sería necesario un plan de acción conjunto, implicando a todos los actores locales, y que debería empezar por cambiar la actual imagen de destino masivo e indiferenciado. Y una tercera vía podría basarse en el retorno a los valores e identidad local, orientación que resulta difícil perfilar cuando se ha ocupado territorio haciendo tabla rasa con la identidad y el valor del paisaje.

\section{UNA APROXIMACIÓN A LA EVOLUCIÓN Y EL FUTURO DE TORREVIEJA DESDE LA TEORÍA DE LA DEPENDENCIA DE LA TRAYECTORIA (PATH DEPENDENCE)}

La evolución de los destinos turísticos ha sido un objeto de investigación fundamental para la geografía que ha dado lugar a diferentes modelos descriptivos y explicativos: desde las propuestas iniciales (Gilbert, 1939; Christaller, 1963) a los modelos de finales de los años setenta y ochenta (Miossec, 1977; Butler, 1980; Young, 1983; Chadefaud, 1987) y de los primeros noventa (Smith, 1991; 1992). Indudablemente, el modelo del ciclo de vida de Butler (1980) ha sido el más utilizado como marco de referencia para el análisis de la evolución de los destinos turísticos. Este modelo describe una secuencia desde el descubrimiento de un lugar turístico hasta su madurez, fase en la que la superación de la capacidad de carga del territorio provoca su declive, si nuevas políticas no son capaces de rejuvenecer el destino. Un esquema simple que, a pesar de sus limitaciones, se ha ido enriqueciendo con numerosos estudios de caso que ponen de manifiesto la compleja evolución de los destinos turísticos.

Recientemente, se han incorporado otras perspectivas de análisis a la evolución de los espacios turísticos. El creciente interés por la teoría de la dependencia de la trayectoria en la geografía económica evolutiva aplicada a la evolución de la economía regional y local, y, de manera creciente, a otros ámbitos de investigación (Martin y Sunley, 2006), ha propiciado su uso en la evolución de los destinos turísticos. En esencia, un proceso o sistema de dependencia de la 
trayectoria es aquel cuyo resultado evoluciona como consecuencia de la propia historia del proceso o sistema (Martin y Sunley, 2006) y depende, en menor medida, de las nociones de eficiencia, racionalidad o equilibrio (David, 1985). La dependencia de la trayectoria se asocia a tres perspectivas básicas: bloqueo tecnológico, derivado de la dependencia de una tecnología por cuestiones históricas cuando, incluso, pueden existir alternativas tecnológicas más eficientes; rendimientos crecientes, que refuerzan la trayectoria existente; e histéresis institucional, cuando las instituciones, formales o informales, preservan una determinada trayectoria de desarrollo (Martin y Sunley, 2006).

Los trabajos de David (1985) y Arthur (1994) describen un modelo básico de dependencia que se ha aplicado al análisis de la evolución de distritos industriales y clusters y también ha sido criticado por diversos autores (Martin, 2010; Martin y Sunley, 2006; Sydow et al., 2005). Dicho modelo está conformado por las siguientes fases: preformación (determinada por la localización de empresas por causas aleatorias o contingentes), creación de la trayectoria (provocada, por ejemplo, por los efectos incipientes de las economías de aglomeración que refuerzan la concentración de empresas), dependencia de la trayectoria (derivada de rendimientos crecientes) y cese de la dependencia como consecuencia de cambios exógenos impredecibles como un incremento de los competidores.

Sobre esta estructura, que puede aplicarse al desarrollo de una tecnología, industria u organización, Martin (2010) propone un nuevo modelo. La fase de preformación no se justificaría por causas accidentales puesto que puede verse favorecida por recursos preexistentes, competencias o habilidades desarrolladas en el sistema económico local. Posteriormente, el periodo de creación de la trayectoria, se explica por las externalidades positivas que comienza a generar una masa crítica de empresas, las cuales se consolidan en el periodo de desarrollo de la trayectoria. Tras este periodo, caben dos posibilidades: la trayectoria como un movimiento hacia una situación de estabilidad o la trayectoria como un proceso dinámico. La primera opción es equivalente al modelo canónico de David y Arthur y está caracterizada por la estabilidad, la dependencia de la tecnología tradicional, y la escasa capacidad de innovación y adaptación al cambio en la economía local o regional. Obviamente, esta trayectoria puede conducir al declive. La segunda posibilidad, la trayectoria como proceso dinámico, es más abierta y refleja una mayor capacidad de cambio y adaptación en el sistema económico, la cual permite conformar una dependencia de la trayectoria que, a su vez, evoluciona. Esta capacidad de adaptación del sistema económico aleja este modelo alternativo de planteamientos exclusivamente deterministas y abre nuevas posibilidades de desarrollo frente a la visión de la teoría de la dependencia de la trayectoria como un conjunto de condicionantes negativos.

En el ámbito del turismo, Brouder y Eriksson (2013) han puesto de relieve las sinergias entre los postulados de la geografía económica evolutiva y la 
evolución de los destinos, con especial énfasis en las aportaciones y limitaciones de la teoría de la dependencia de la trayectoria, mientras que el modelo alternativo de Martin (2010) se ha aplicado recientemente al estudio de la evolución de los destinos turísticos. Ma y Hassink (2013) han contrastado el modelo del ciclo de vida de Butler (1980) con la teoría de la dependencia de la trayectoria y la han aplicado a la Goald Coast australiana, así como a la región de Guilin (China) (Ma \& Hassink, 2014). Halkier \& Therkelsen (2013), en su estudio sobre el Norte de Jutlandia (Dinamarca), introducen el concepto de plasticidad, o cambio incremental, dentro de la trayectoria de desarrollo dominante, un enfoque análogo al que identifica la trayectoria como un proceso dinámico. Por otra parte, Gill y Williams (2014) utilizan el marco teórico de la creación de la trayectoria para explicar el cambio operado en Whistler, destino de montaña de British Columbia (Canadá), desde un modelo de crecimiento a un desarrollo basado en los principios de la sostenibilidad. Por último, desde la perspectiva de la geografía económica evolutiva y relacional, Sanz y Anton (2014) plantean un nuevo enfoque de la evolución de los destinos turísticos basado en la interacción de tres factores que influyen y singularizan la evolución de cada destino: la acción de los agentes del destino; el contexto (social, económico, ambiental y político, así como las tendencias de mercado a escala local y global); y la dependencia de la trayectoria (el resultado de acciones y decisiones tomadas en el pasado).

\section{La conformación de la trayectoria dependiente en Torrevieja y su evolución}

El análisis de la dependencia de la trayectoria sintetizada en la figura 5, se ha elaborado a partir de unos indicadores que reflejan los procesos de desarrollo urbano-turísticos del municipio y el papel de los agentes públicos y privados que explican las dinámicas para la configuración del modelo territorial y turístico de Torrevieja. Entre estos indicadores, sobresalen determinadas variables demográficas (evolución de la población y composición por edad y nacionalidad) y otras relativas al sector inmobiliario (número de viviendas construidas y porcentaje de viviendas principales). La información sectorial turística, tanto de desde el punto de vista de la oferta como de la demanda, pasa a un segundo plano ante el notable peso del sector inmobiliario en la estructura económica local.

Desde la perspectiva del modelo de la trayectoria dependiente de Martin (2010), la fase de preformación (s. xIx hasta mediados de la década de los sesenta del s. xx) se remonta a las prácticas balnearias del siglo siglo XIX, merced a la presencia de recursos geoturísticos (clima y mar), una buena accesibilidad relativa y la debilidad de la base económica primaria (explotación de la sal, pesca y comercio marítimo) que facilita la introducción de actividades 
balnearias. La actividad turística está reservada a personas acomodadas y se manifiesta desde el punto de vista territorial en la construcción de villas y paseos marítimos de la fachada costera. Iniciado el siglo xx se amplía el espectro de demanda y, además de los propietarios de villas, los veraneantes alquilan casas en la localidad.

A partir de estas prácticas se configura el periodo de creación de la trayectoria (mediados de los sesenta hasta el inicio de los ochenta) a mediados de la década de los sesenta, que se traduce en un proceso de paulatino desarrollo inmobiliario favorecido por el escaso valor agrícola de amplios sectores de suelo rústico, el predominio de la propiedad media-grande y la creciente penetración de empresas foráneas de promoción inmobiliaria. La construcción de urbanizaciones desborda el núcleo tradicional y se amplía el continuo urbano-turístico a lo largo del eje litoral. A partir de los años setenta se acrecienta como tipología edificatoria la de edificios de apartamentos en altura, frente a las viviendas unifamiliares de planta baja, lo que se traduciría en una notable densificación de la trama urbana preexistente y de los nuevos ensanches.

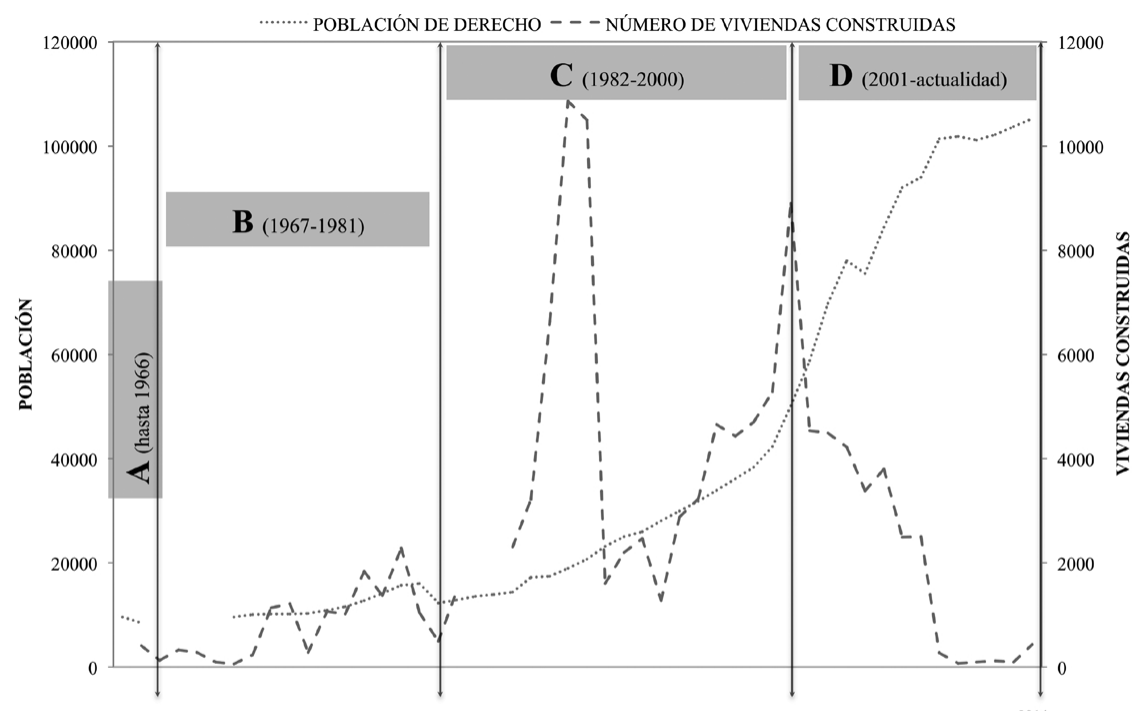

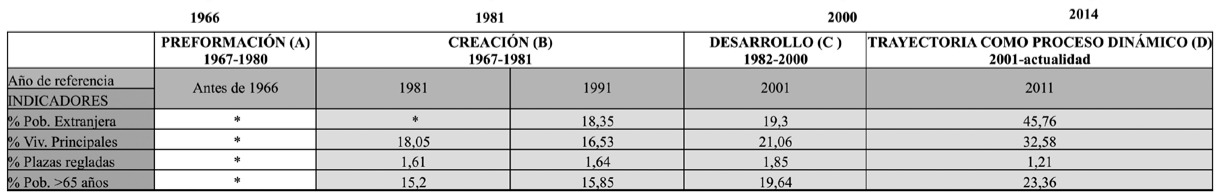

* Para este periodo los datos no están disponibles.

Figura 5. Evolución de Torrevieja a partir de la teoría de la dependencia de la trayectoria. Fuente: Instituto Nacional de Estadística (INE); Vera (1987); Mazón y Aledo (2004).

Elaboración propia. 
Este proceso tiene lugar sin un plan general capaz de definir la estructura funcional y orgánica del territorio municipal. Antes de la aprobación del PGOU de 1973 ya existían 9 planes parciales aprobados. El nuevo PGOU formaliza la construcción y expansión del uso residencial de los años anteriores y la clasificación de suelo para continuar el proceso de crecimiento. Mientras se mantiene el desarrollo lineal de la edificación en la costa y se inicia otro proceso de edificación en suelos más baratos del interior, en el contorno de la laguna, bastantes de ellos sin vistas al mar.

El desarrollo de la trayectoria (desde los años ochenta al inicio del milenio) tiene lugar en la segunda mitad de los ochenta, sobre todo a partir de la aprobación del PGOU de 1986, que permite la eclosión del modelo residencial, orientado a rentas con poder adquisitivo medio-bajo, con intensos ritmos de crecimiento que disparan el número de viviendas y de residentes. Irrumpe el bungalow adosado como tipología constructiva que estandariza el producto inmobiliario de bajo coste. Paralelamente, se populariza el modelo de Torrevieja en los medios de comunicación.

El Plan de 1986 y las numerosas modificaciones puntuales a las que se somete permiten la urbanización de todo el término municipal, salvo el área sustraída a la presión urbanizadora gracias a la declaración del Parque Natural de las Lagunas de Torrevieja y La Mata (previamente paraje natural) en 1989, sintomáticamente declarado en una coyuntura de crecimiento inmobiliario explosivo puesto que en 1988 y 1989 se construyeron más de 20.000 viviendas en Torrevieja. No obstante, el inicio de los noventa supone una ralentización del ritmo de crecimiento debido a la crisis económica internacional, que se recupera con las medidas económicas de depreciación de la peseta a partir de 1993. Durante este periodo, se produce un espectacular incremento de la población (38.632 habitantes) y, sobre todo, de las viviendas de nueva construcción (82.833). Se consolida un modelo económico basado en la construcción y los servicios para un volumen de población creciente, en la que sobresalen dos rasgos: un índice de envejecimiento elevado (el 19,6\% de la población tiene más de 65 años en 2001) y un porcentaje significativo de población de origen extranjero $(19,3)$. Las viviendas principales sólo suponen el 21\% del total (102.355), cifra indicativa de un enorme parque inmobiliario de potencial uso turístico que explica que las plazas en alojamiento turístico reglado (hoteles, apartamentos turísticos y campings) sólo supongan un $1,8 \%$ de la capacidad de alojamiento turístico en el municipio.

Los primeros años del nuevo milenio no implican un cambio en el modelo de crecimiento pero sí un proceso de reflexión público asociado simbólicamente al segundo centenario de la fundación administrativa de Torrevieja auspiciado por el Ayuntamiento, que, a su vez, plantea toda una serie de iniciativas y proyectos con impacto sobre el modelo territorial y turístico del municipio. Estas 
propuestas se enmarcan en una coyuntura de intenso crecimiento inmobiliario que incrementa de manera notable los ingresos municipales y, por tanto, la capacidad de gasto e inversión de la Administración Local. Estas iniciativas suponen una novedad sobre la etapa anterior que cabe asimilar a la trayectoria como proceso dinámico (desde el inicio del milenio a la actualidad) en la medida en que se detectan propuestas, hasta cierto punto novedosas, con distinto alcance sobre la evolución del destino.

Estas iniciativas pueden agruparse en cuatro ámbitos: las políticas activas de empadronamiento; las medidas para una mayor eficiencia en la gestión medioambiental; la puesta en valor de recursos patrimoniales; y la creación de nuevas infraestructuras culturales y deportivas. Las políticas de fomento del empadronamiento se basaron en ayudas directas a estudiantes y pensionistas, a nuevos matrimonios y a la gratuidad del transporte público. En un contexto de bonanza económica, con un flujo inmigratorio significativo, estas medidas han surtido efecto puesto que el porcentaje de viviendas principales ha crecido desde el 21,1\% (2001) al 32,6\% (2011).

Desde el punto de vista ambiental, el crecimiento urbano-turístico ha ido acompañado de una mejora de la gestión que ha paliado, solo en parte, la creciente presión humana sobre el territorio. En particular, resulta destacable la gestión del ciclo del agua en el que se han reducido considerablemente las pérdidas en la red de distribución, a la vez que se alcanzan elevados porcentajes de reutilización del agua depurada para riego agrícola, de parques y jardines y de vecinos campos de golf. Asimismo, se han introducido mejoras en la recogida selectiva y el tratamiento de residuos.

En el plano de la puesta en valor de recursos patrimoniales destacan las actuaciones derivadas del Plan de Excelencia de Torrevieja (2001-2003), la creación del parque del Molino del Agua y los proyectos sobre la revalorización del recinto de las Eras de la Sal, que no ha llegado a cristalizar. Torrevieja fue incluida en el Programa de Planes de Excelencia para la renovación de destinos maduros (planes trianuales cofinanciados por el Ministerio, la Comunidad Autónoma y el municipio beneficiado). No obstante, en lugar de plantearse un enfoque carácter integral para el municipio, el Plan de Excelencia de Torrevieja se centró, básicamente, en la adecuación como Vía Verde del trazado abandonado del ferrocarril Torrevieja-Albatera y en la creación del Centro de Interpretación de la Industria Salinera, en un antiguo almacén de mercancías de RENFE. El Plan también incorpora el polémico y desafortunado proyecto de Parque de Relajación en la Punta de la Víbora, diseñado por el arquitecto japonés Toyo Ito, actualmente abandonado.

En la línea de esta última iniciativa, el Ayuntamiento trata de promover proyectos con un supuesto carácter emblemático. Además del balneario de Toyo Ito, se encarga al arquitecto Santiago Calatrava un proyecto de remodelación 
del puerto que no llegará a ver la luz. No obstante, la capacidad inversora municipal queda patente en la construcción de diferentes equipamientos culturales y deportivos: Palacio de la Música (1999); la Ciudad Deportiva, que cuenta con el Palacio de Deportes Infanta Cristina (2000); o el Teatro Auditorio de Torrevieja (2006). En algunos casos, no exentos de polémica ${ }^{9}$

En este periodo se plantea una Modificación Puntual del PGOU (la número 74, aprobada por la Conselleria de Territorio y Vivienda, en 2006) con la finalidad de fomentar el uso hotelero. El texto que justifica dicha Modificación reconoce claramente el elevado consumo de suelo del modelo residencial, las grandes exigencias de infraestructuras y de prestación de servicios públicos y su limitado efecto dinamizador de la economía local. La referida modificación permite un incremento de la edificabilidad para el uso hotelero, variable según el tipo de suelo. Sin embargo, esta medida no ha surtido el efecto esperado y la oferta hotelera continúa estancada.

Las iniciativas desarrolladas no rompen con la trayectoria dominante de crecimiento inmobiliario, ni parece ese su objetivo; pero, además, no tienen capacidad para generar una nueva trayectoria de destino basada, en todo caso, en el residencialismo y en el poder dinamizador de proyectos públicos cuyo impacto en la estructura económica local resulta marginal. En este periodo se aprecia de manera todavía más visible que en la etapa anterior la coevolución de los destinos con la coyuntura económica nacional e internacional puesto que la crisis de 2007 provoca un acusado decrecimiento del ritmo de construcción de viviendas, e, incluso, se aprecia una pérdida de población, difícil de evaluar porque parece deberse más a una regularización del Padrón de Habitantes que a un descenso real del número de residentes registrados.

Las diferencias en el periodo intercensal (2001-2011) vienen marcadas por un aumento de las viviendas (39.494), claramente inferior al de la etapa anterior, aunque se incrementa la cuota de viviendas principales y se produce un crecimiento notable de la población (39.144 habitantes), cuya estructura global experimenta dos cambios significativos: el incremento de la cuota de residentes de origen extranjero hasta el $45,7 \%$ y del índice de envejecimiento, que alcanza el 23,4\%. En 2001, la distribución de residentes por nacionalidades presentaba un predominio de los ciudadanos de Reino Unido ( $28 \%$ de los extranjeros) y de Alemania (17\%). Pero, en 2011, la composición resulta más compleja y diversa ya que se mezclan inmigrantes jubilados y de tipo laboral: los ciudadanos procedentes de Reino Unido bajan al 19\% mientras que los rusos ocupan el segundo lugar (11\%), configurando la segunda colonia de esta nacionalidad en España,

9. Torrevieja pide al juez ser acusación en la investigación de los sobrecostes del Teatro. Diario Información de Alicante. Julio de 2015. Disponible en: http://www.diarioinformacion.com/ vega-baja/2015/07/18/ayuntamiento-pide-juez-acusacion-investigacion/1656917.html. 
según datos del INE, y los marroquíes el tercero (6,5\%), a los que siguen ciudadanos de otras nacionalidades, con cuotas en torno al 5\%: rumanos, ucranianos, búlgaros, alemanes y suecos.

\section{A MODO DE CONCLUSIÓN ¿QUÉ TRAYECTORIA FUTURA PARA TORREVIEJA COMO DESTINO TURÍSTICO?}

Torrevieja es el paradigma de un destino turístico sustentado en unas raíces turísticas desde época histórica, asociado a la percepción y disfrute del mar. Su configuración como ciudad turística de masas ha sido rápida y centrada en exclusiva en la vertiente inmobiliaria. Por tanto, la opción residencial es la vertiente dominante del sistema local. Por sus evidentes y complejas repercusiones territoriales y urbanísticas, las respuestas de futuro han de sustentarse en el mismo territorio que le da sentido, en su recuperación y valorización, como factor de competitividad. Urge un debate sobre la ciudad generada por el turismo y su futuro, más allá de la ordenación necesaria del conglomerado de actuaciones y de las afecciones ambientales. Pero ese debate sobre el destino turístico ha de hacerse de un modo integral, en el que confluyen numerosos aspectos que harían que la ciudad de ocio recuperase su imagen y su dinámica como lugar atractivo: equipamientos e infraestructuras para residentes y turistas, accesibilidad, calidad y variedad del alojamiento, funcionamiento del destino durante todo el año, dinamización de la oferta comercial y de ocio, nuevos productos turísticos y hosteleros, valorización de activos culturales, protección de áreas de interés natural, mejora de la gestión y gobernanza participativa.

A partir de todos estos aspectos, ¿cabe pensar en la creación de una nueva trayectoria para el destino? La respuesta a esta pregunta es compleja. El desarrollo urbanístico de Torrevieja presenta un alto grado de irreversibilidad y dificulta un cambio de modelo de carácter radical. Además, este modelo lleva implícito el riesgo de seguir perpetuándose ante una eventual recuperación del ciclo económico y la demanda inmobiliaria. Por tanto, se vislumbran dos escenarios poco deseables que deberían evitarse: la progresiva degradación del modelo de construcción masiva y su correlato turístico-residencial o la recuperación de la producción inmobiliaria de bajo valor añadido, que no resuelve sino agrava los problemas estructurales del destino, aunque es rentable para el sector de la construcción.

Frente a ambos escenarios es aconsejable el desarrollo de políticas más proactivas y ambiciosas, capaces de cualificar el modelo territorial y relanzar, bajo nuevos parámetros, la actividad turística en el municipio. Sería poco realista referirse a la creación de una nueva trayectoria ante las dificultades mencionadas, pero sí cabe esperar una mayor capacidad de innovación en la gestión del destino que reconduzca las dinámicas negativas del modelo turístico 
y desarrolle todas sus potencialidades. Para este nuevo enfoque de gestión se plantean las siguientes propuestas:

1. Es necesaria una estrategia a largo plazo y un proyecto integral de ciudad que potencie, dinamice y diversifique las funciones económicas, vertebre las piezas urbanas mediante la recuperación de la centralidad del casco tradicional, mejore la escena urbana y recupere el patrimonio, los valores y la identidad local. Dicha estrategia debe plantearse en el marco de una verdadera gobernanza de destino, abierta y participativa, y orientarse a la mejora de la calidad de vida de los residentes con el objetivo de potenciar Torrevieja como residencia permanente, de acuerdo con la tendencia experimentada en los últimos años, pero desde nuevos parámetros.

2. En el ámbito comarcal, Torrevieja debe desempeñar un papel de liderazgo en servicios comerciales, culturales y de ocio que potencie su capacidad de atracción de visitantes y turistas. Una posibilidad indisociable de una mejor vertebración territorial que palie los efectos de la dispersión urbanística y de la actual localización periférica de la oferta comercial en detrimento de la ciudad tradicional.

3. La creación de nuevos productos turísticos constituye una prioridad. Se observa un desarrollo incipiente de productos como el náutico o el turismo de naturaleza que es necesario potenciar. Una oferta realmente estructurada en productos turísticos facilita la diversificación, con los consiguientes beneficios en creación de nuevas empresas y de empleo, contribuye a la desestacionalización y eleva el nivel de gasto en destino. Entre los productos que cuentan con mayor potencialidad cabe destacar el náutico, activo, naturaleza (con sus diferentes variantes, entre las que se encuentra el turismo ornitológico), deportivo (vinculado a las instalaciones deportivas que concentra el municipio) o el gastronómico, sin descartar, desde una perspectiva comarcal, el golf, por la vecindad de instalaciones en el entorno inmediato. Mención especial merece el turismo de salud como un mercado de oportunidad que cuenta con factores de desarrollo favorables en Torrevieja como el clima, la concentración de residentes extranjeros, con sus vínculos con los países de origen, y la presencia de un sector sociosanitario avanzado, entre otros.

4. La estructuración de nuevos productos tiene como barrera principal el déficit de oferta de alojamiento comercial (hoteles, apartamentos, campings, etc.), en cantidad y en calidad. Este problema no se ha resuelto con medidas urbanísticas y se agrava con la competencia desleal que supone la creciente comercialización de viviendas de uso turístico a 
través de Internet. A pesar de las dificultades, resulta esencial incrementar este tipo de oferta para atraer otros segmentos de demanda al destino.

5. La cualificación del modelo turístico debe ir acompañada de un reposicionamiento de la imagen del destino que supere las connotaciones negativas de la imagen de Torrevieja y potencie sus atributos funcionales y simbólicos de una manera renovada y atractiva.

Estas propuestas, de carácter forzosamente sintético, son indicativas de la necesidad de redefinir el modelo turístico de Torrevieja, una tarea compleja que evidencia las dificultades de superar una trayectoria dependiente que ha configurado un destino turístico excesivamente marcado por dinámicas inmobiliarias, las cuales se han ido retroalimentando para provocar un desproporcionado proceso de crecimiento cuyo estancamiento actual hace aflorar muchas dudas acerca del futuro del destino. Sin embargo, esta incertidumbre no debería interpretarse de manera coyuntural o cíclica puesto que demanda soluciones estructurales que permitan un replanteamiento del modelo turístico local y, en la medida de lo posible, la creación de una nueva trayectoria turística, algo en lo que parece haber cada vez más compromiso social, tras haber aflorado la situación crítica del municipio y la necesaria reorientación como vía de futuro.

\section{BibLIOGRAFÍA}

Anton Clavé, S. (coord.) (2005): Planificación territorial del turismo. Editorial UOC. Barcelona, $216 \mathrm{pp}$.

Anton Clavé, S. y González Reverté, F. (coords) (2008): A propósito del turismo. La construcción social del espacio turístico. Editorial UOC. Barcelona, 346 pp.

Anton Clavé, S.; Fernández Tabales, A. y González Reverté, F. (2008): Los lugares turísticos, en Anton Clavé, S. y González Reverté, F. (coords): A propósito del turismo. La construcción social del espacio turístico. Editorial UOC. Barcelona, pp.103-206.

ARTHUR, W.B. (1994). Increasing returns and path dependence in the economy. Ann Arbor: University of Michigan Press.

BROUDER, P. \& ERIKSSON, R. H. (2013): «Tourism evolution: on the synergies of tourism studies and evolutionary economic geography», en Annals of Tourism Research. DOI:10.1016/j.annals.2013.07.001.

BUTLER, R.W (1980): «The concept of a tourist area cycle of evolution: implications for management of resources», en The Canadian Geographer, n. ${ }^{\circ} 24$ (1), pp. 5-12

Casado-Diaz, M.A. (1999) 'Socio-demographic impacts of residential tourism: a case study of Torrevieja', en The International Journal of Tourism Research, n. ${ }^{\circ}$ 1, pp. 223-237.

Celdrán Bernabeu, M.A. y Azorín Molina, C. (2004): «La explotación industrial de las Salinas de Torrevieja (Alicante)», en Investigaciones Geográficas, n. ${ }^{\circ}$ 35, pp. 105-132. 
Chadefaud, M. (1987): Aux origines du tourisme dans les pays de l'Adour (Du mythe à l'espace: un essai de géographie historique). Pau: Département de Géographie et d'Aménagement de l'Université de Pau.

Christaller, W. (1963): «Some Considerations of Tourism Location in Europe: The Peripheral Regions-Underdeveloped Countries-Recreation Areas», en Regional Science Association Papers, n. ${ }^{\circ}$ 12(1), pp. 95-105.

DAVID, P. A. (1985): «Clio and the economics of QWERTY», en American Economic Review, n. ${ }^{\circ} 75$, pp. 332-337.

Díaz Ameneiro, P. (2015): Pateando el litoral. La construcción del territorio del turismo de masas. Tesis Doctoral (inédita), Escola Tècnica Superior d' Arquitectura de Barcelona, DUOT, Universitat Politècnica de Catalunya, 3 vols + anexo cartográfico.

EspadA, A. (2007): Ebro Orbe. Ediciones Tentadero. Barcelona, pp. 232-234.

Fernández, S. y BARRAdo, D. (2001): «El desarrollo turístico-inmobiliario de la España Mediterránea e insular frente a sus referentes internacionales (Florida y la Costa Azul): un análisis comparado», en Cuadernos de Turismo, Universidad de Murcia, n. ${ }^{\circ}$ 27, pp-373-402.

Galant Torregrosa, M.; Sala Aniorte, F. y otros (2004): El espacio geográfico de Torrevieja a través del tiempo. Instituto Municipal de Cultura Joaquín Chapaprieta Torregrosa. Torrevieja.

Generalitat Valenciana (2008): Plan de Espacios Turísticos de la Comunidad Valenciana. Consellería de Turisme. Valencia.

GILBERT, E.W. (1939): «The growth of inland and seaside health resorts in England», en Scottish Geographical Magazine, n. ${ }^{\circ}$ 55, pp.16-35.

Gill, A. y Williams, P. (2014): «Applying a path creation lens to understanding resort evolution», en Chien, P. Monica. CAUTHE 2014: Tourism and Hospitality in the Contemporary World: Trends, Changes and Complexity. Brisbane: School of Tourism, The University of Queensland, pp. 851-854.

Halkier, H. y A. Therkelsen (2013): «Breaking out of Tourism Destination Path Dependency? Exploring the Case of Coastal Tourism in North Jutland, Denmark», en German Journal of Economic Geography, n. ${ }^{\circ}$ 57(1-2), pp. 39-51.

Instituto Nacional de Estadística (2015): Indicadores Urbanos, Disponible en: http:// www.ine.es/ss/Satellite?L=es_ES\&c=INESeccion_C\&p=1254735110672\&pagen ame=ProductosYServicios\%2FPYSLayout\&param1=PYSDetalleFichaSeccionU A\&param3 $=1259944561392 \&$ charset_ $=U T F-8 \& c i d=1259944663444$, Acceso: $17-09-2015$

MA, M. y Hassink, R. (2014): «Path dependence and tourism area development: the case of Guilin, China», en Tourism Geographies: An International Journal of Tourism Space, Place and Environment., n. ${ }^{\circ} 16$ (4), pp. 580-597.

MA, M \& HAssink, R. (2013): «An evolutionary perspective on tourism area development», en Annals of tourism research, n. ${ }^{\circ} 41$, pp. 89-109.

MARTIN, R. (2010): «Roepke lecture in economic geography-Rethinking regional path dependence: Beyond lock-in to evolution», en Economic Geography, n. ${ }^{\circ}$ 86, pp. $1-27$. 
Martin, R. \& Sunley, P. (2006): «Path dependence and regional economic evolution», en Journal of Economic Geography, n. ${ }^{\circ} 6$, pp. 395-437.

Mazón Martínez, T. y Aledo Tur, A. (2004): «La masificación del turismo residencial: el modelo Torrevieja», en Turismo, Ocio y Deporte: VIII Congreso de Sociología, Universidade da Coruña, pp. 275-286

Morales Gil, A. y Vera Rebollo, J.F. (1989): La Mancomunidad de los Canales del Taibilla. Instituto Universitario de Geografía de la Universidad de Alicante y Academia Alfonso X El Sabio de Murcia, 133 pp.

PiÉ Ninot, R. (2013): «Las arquitecturas del turismo: las piezas mínimas», en Pié, R. y Rosa, C.J. (eds.): Turismo líquido. Barcelona: Instituto Hábitat, Turismo y Territorio y Digital Politècnica (UPC), pp. 14-37.

PIÉ Ninot, R. y RosA, C.J. (2013): «Un turismo sin arquitectura o una arquitectura sin argumento», en Pié, R. y Rosa, C. (eds.): Turismo líquido. Barcelona: Instituto Hábitat, Turismo y Territorio y Digital Politècnica (UPC), pp. 6-12.

Proyecto METASIG (2002): Área Piloto del litoral y prelitoral del Bajo Segura (Comunidad Valenciana). Análisis y Diagnóstico. Documento de síntesis. Instituto Universitario de Geografía de la Universidad de Alicante.

Pujol, J.A. (2003): Guía de flora del Parque Natural de las lagunas de La Mata y Torrevieja. Instituto Municipal de Cultura Joaquín Chapaprieta Torregrosa. Torrevieja, $308 \mathrm{pp}$.

Pujol, J.A. y Calvo, J.F. (1997): Torrevieja, Cuadernos para su estudio. I. Medio Natural. Instituto Municipal de Cultura Joaquín Chapaprieta Torregrosa. Torrevieja, $251 \mathrm{pp}$.

Rebollo Ortega, F. (2007): Torrevieja a través del tiempo. Cronología 1238-2004. Instituto Municipal de Cultura Joaquín Chapaprieta Torregrosa. Torrevieja.

Rosa, C.J. (2013): «El turismo como futuro: la ciudad del ocio», en Pié, R. y Rosa, C. (eds.): Turismo líquido. Instituto Hábitat, Turismo y Territorio y Digital Politècnica (UPC). Barcelona, pp. 38-49.

Rovira Soto, M.T. (2008): «Consideraciones metodológicas para el estudio de los nuevos procesos territoriales y turísticos en destinos litorales consolidados», en Ivars Baidal, J.A. y Vera Rebollo, J.F. (eds): Espacios turísticos. Mercantilización, paisaje e identidad. AGE y Universidad de Alicante. Alicante, pp. 183-192.

SANZ-IbÁÑEZ, C. y ANTON, S. (2014): «The evolution of destinations: towards an evolutionary and relational economic geography approach», en Tourism Geographies, pp. 563-579 DOI:10.1080/14616688.2014.925965.

Smith, R.A. (1991): Beach resorts: A model of development evolution. Landscape and Urban Planning 21: 189-210

SмIth, R.A. (1992): «Beach Resort Evolution: Implications for Planning», en Annals of Tourism Research, n. ${ }^{\circ} 19$ (2), pp. 304-322.

Vera Rebollo, J.F. (1984): «Mutaciones espaciales producidas por el turismo en el municipio de Torrevieja», Investigaciones Geográficas, Universidad de Alicante, n. ${ }^{\circ} 2$, pp. 115-138.

Vera ReBOllo, J.F. (1987): Turismo y urbanización en el litoral alicantino. Instituto J. Gil-Albert y Colegio Oficial de Arquitectos de Alicante. Alicante, 441 pp. 
Vera Rebollo, J.F. (2001): «El ocio organizado: los paraísos turísticos», en Año mil, año dos mil. Dos milenios en la Historia de España. Sociedad Estatal España Nuevo Milenio. Madrid, pp.453-474.

Vera Rebollo, J.F. (2005): «El auge de la función residencial en destinos turísticos del litoral mediterráneo: entre el crecimiento y la cualificación», en Papers de Turisme, n. ${ }^{\circ} 37-38$, pp. 95-114.

Vera Rebollo, J.F. e Ivars Baidal, J.A. (2003): «Measuring sustainability in a mass tourist destination: Pressures, perceptions and policy responses in Torrevieja, Spain» en Journal of Sustainable Tourism, n. ${ }^{\circ}$ 11, Issue 2-3, pp. 181-203.

Young, B. (1983): «Touristisation of traditional Maltese fishing-farming villages», en Tourism Management, N. ${ }^{\circ} 4(1)$, pp.35-41. 